\title{
IMPLEMENTASI KEBIJAKAN REHABILITASI PENGGUNA NARKOBA DI KOTA MAKASSAR
}

\author{
Haerana \\ Dosen Universitas Muhammadiyah Makassar
}

\begin{abstract}
ABSTRAK
Penelitian ini bertujuan untuk mengungkap bagaimana mekanisme implementasi kebijakan yang dikhususkan pada bidang Rehabilitasi pengguna narkoba serta berbagai faktor yang mempengaruhinya. Penelitian ini menggunakan metode penelitian kualitatif dengan pendekatan studi kasus. Pengumpulan data dilakukan dengan tiga cara yakni wawancara, observasi dan studi dokumentasi. Hasil penelitian ini menunjukkan bahwa implementasi kebijakan rehabilitasi pengguna narkoba sudah dilaksanakan dengan baik walaupun terdapat satu indikator yang belum berjalan dengan baik. Indikator keberhasilan dari implementasi kebijakan tersebut dapat terlihat dari kesuksesan dalam pelaksanaan program mengintensifkan Wajib Lapor Pecandu Narkotika, pemberian pelayanan rehabilitasi medis dan rehabilitasi sosial kepada penyalahguna narkoba, pembangunan kapasitas lembaga rehabilitasi medis dan rehabilitasi sosial. Dan indikator yang belum berjalan dengan baik adalah program pembinaan lanjut kepada mantan penyalahguna, korban penyalahgunaan dan pecandu narkoba.
\end{abstract}

Kata Kunci: implementai kebijakan, rehabilitasi pengguna narkoba

\section{PENDAHULUAN}

Badan Narkotika Nasional adalah sebuah lembaga pemerintahan non kementrian Indonesia yang mempunyai tugas pemerintahan dibidang pencegahan dan pemberantasan narkotika.Badan Narkotika Nasional dipimpin oleh seorang kepala yang bertanggung jawab kepada presiden melalui Kepala Kepolisian Republik Indonesia. Dasar hukum Badan Narkotika Nasional sebagai lembaga pemerintahan non kementrian adalah Peraturan Presiden Nomer 23 Tahun 2010 tentang badan Narkotika Nasional.

Badan Narkotika Nasional (BNN) Provinsi Sulawesi Selatan menyebutkan ada enam wilayah di Makassar yang masuk dalam zona merah atau rawan terhadap peredaran Narkoba. Keenam wilayah tersebut adalah Kerung-kerung, Rajawali, Pampang, Cokonuri, Kandea, dan Tinumbu. Penetapan tersebut dilakukan menyusul daerah-daerah ini menjadi tempat kejadian perkara (TKP) kepolisian beberapa tahun terakhir.

Pesatnya peningkatan jumlah pengguna narkoba tidak terlepas dari karakteristik Kota Makassar sebagai kota metropolitan dengan pertumbuhan tempat hiburan malam dan hotel yang terus meningkat pula. Dan didukung dengan fasilitas internet sehingga membuat masyarakat dan pengedar gampang melakukan transaksi barang haram itu. Selain itu, adanya akses masuk pengedar narkoba dari dua pintu yaitu Pelabuhan dan Bandara yang dimiliki oleh Kota Makassar menjadikan daerah ini sasaran empuk bagi para mafia narkoba dalam memperkuat jaringannya. Secara kuantitas jumlah pengguna narkoba setiap tahunnya mengalami peningkatan secara signifikan, oleh karena itu diperlukan upaya pencegahan dan penanggulangan pengguna narkoba yang lebih serius dan sistematis. 


\section{TINJAUAN PUSTAKA}

Carl Frederic dalam Agustino (2008:7) menjelaskan bahwa kebijakan adalah serangkaian tindakan atau kegiatan yang diusulkan oleh seseorang, kelompok atau pemerintah dalam suatu lingkungan tertentu di mana terdapat beberapa hambatan (kesulitan-kesulitan) dan kemungkinan kemungkinan (kesempatankesempatan) di mana kebijakan tersebut diusulkan agar berguna dalam mengatasinya untuk mencapai tujuan yang dimaksud. Evita (2013) Pembuatan kebijakan merupakan suatu tindakan yang ditetapkan dan dilaksanakan oleh pemerintah dan berorientasi pada upaya pencapaian tujuan demi kepentingan masyarakat.

Sejumlah pengertian kebijakan di atas maka dapat disimpulkan bahwa kebijakan adalah keputusan yang bersumber dari seseorang, sekelompok orang atau pemerintah yang berkepentingan dimana isi dari keputusan tersebut menyangkut serangkaian kegiatan yang saling berhubungan satu sama lain dan dimaksudkan untuk mencapai tujuan tertentu.

Kebijakan merupakan upaya untuk memahami dan mengartikan :

1. Apa yang dilakukan (atau tidak dilakukan) oleh pemerintah mengenai suatu masalah;

2. Apa yang dapat menyebabkan atau yang dapat mempengaruhinya;

3. Apa pengaruh dan dampak dari kebijakan publik tersebut

Salah satu bentuk kebijakan yang paling populer adalah kebijakan publik, hal ini dikarenakan kebijakan publik terkait dengan pencapaian tujuan negara untuk mensejahterahkan warga negaranya. Menurut RC Chandler dan JC Plano dalam Syafi'ie (2006:105) yang mengatakan bahwa kebijakan publik adalah pemanfaatan yang strategis terhadap sumber daya yang ada untuk memecahkan masalah publik.
Dalam konteks lain, Islamy dalam Anggara (2012:501) mengemukakan bahwa kebijakan publik merupakan serangkaian tindakan yang ditetapkan dan dilaksanakan atau tidak dilaksanakan oleh pemerintah dengan berorientasi pada tujuan tertentu demi kepentingan seluruh masyarakat.

Terdapat empat pengertian tentang kebijakan publik :

1. Kebijakan publik dalam bentuk perdananya berupa penetapan tindakan pemerintah

2. Kebijakan publik tidak cukup hanya dinyatakan tetapi harus dilaksanakan dalam bentuk yang nyata.

3. Kebijakan publik baik untuk melakukan sesuatu mempunyai dan dilandasi dengan maksud dan tujuan tertentu.

4. Kebijakan publik harus senantiasa ditujukan bagi kepentingan seluruh anggota masyarakat.

Ripley dan Franklin menjelaskan bahwa implementasi adalah apa yang terjadi setelah undang-undang ditetapkan yang memberikan otoritas program, kebijakan, keuntungan (benefit), atau suatu jenis keluaran yang nyata (tangible output). Implementasi mencakup tindakantindakan oleh beberapa aktor, khususnya para birokrat, yang dimaksudkan untuk membuat program berjalan (Winarno, 2008:145).

Van Meter dan Van Horn dalam Solihin (2007:146), dimana keduanya membatasi implementasi kebijakan sebagai tindakan-tindakan yang dilakukan oleh individu-individu atau kelompok pemerintah maupun swasta yang diarahkan untuk mencapai tujuan-tujuan yang telah ditetapkan dalam keputusan-keputusan kebijakan sebelumnya. Tindakan-tindakan ini mencakup usaha-usaha untuk mengubah keputusan-keputusan menjadi tindakan operasional dalam kurun waktu tertentu maupun dalam rangka melanjutkan usaha untuk mencapai perubahan yang ditetapkan oleh keputusan-keputusan kebijakan. 
Program Rehabilitasi yang akan dikaji dalam penelitian ini adalah sejumlah program rehabilitasi sebagaimana yang tertuang di dalam Instruksi Presiden no. 12 tahun 2011 tentang Kebijakan dan strategi nasional pencegahan dan pemberantasan penyalahgunaan dan peredaran gelap narkoba (P4GN) untuk periode tahun 2011 - 2015. Kebijakan dan strategi nasional ini adalah program pemerintah sebagai salah satu upaya untuk mewujudkan cita-cita bangsa "Indonesia Negeri Bebas Narkoba" dan sebagai refleksi atas semakin maraknya mafia narkoba menggencarkan aksinya di sejumlahnya daerah di Indonesia. Dari data Badan Narkotika Nasional dapat diketahui adanya kecendrungan peningkatan secara signifikan penyalahgunaan narkoba di setiap tahunnya.

Dalam Inpres no. 12 Tahun 2011 dijelaskan bahwa dalam bidang Rehabilitasi memfokuskan pada :

1. Upaya mengintensifkan wajib lapor pecandu narkotika.

2. Upaya memberikan pelayanan rehabilitasi medis dan rehabilitasi sosial kepada penyalahguna, korban penyalahgunaan dan pecandu narkoba.

3. Upaya pembangunan kapasitas lembaga rehabilitasi medis dan rehabilitasi sosial secara prioritas berdasarkan kerawanan daerah penyalahgunaan narkoba.

4. Upaya pembinaan lanjut kepada mantan penyalahguna, korban penyalahgunaan dan pecandu narkoba.

\section{METODE PENELITIAN}

Pendekatan penelitian yang dilakukan untuk menjawab pertanyaan penelitian tersebut yaitu kualitatif dengan menggunakan tipe studi kasus. Studi kasus merupakan penelitian tentang sesuatu 'kesatuan sistem' berupa program, kegiatan, peristiwa yang terkait oleh tempat, waktu dan ikatan tertentu (Ghony dan Almanshur, 2012:61). Dan untuk menjaga objektivitas peneliti sebagai instrument, maka digunakan pokok-pokok butir wawancara, panduan observasi, dan panduan studi dokumentasi sebagai penuntun mengajukan pertanyaan, pengamatan dan studi dokumentasi. Teknik analisis data yang digunakan dalam penelitian ini merupakan kegiatan yang bertujuan untuk mengolah data-data yang sudah di peroleh melalui kegiatan wawancara, observasi dan studi dokumentasi. Teknik yang digunakan adalah analisis data kualitatif dengan langkah-langkah sebagi berikut: mereduksi data, penyajian data, verifikasi dan penarikan kesimpulan.

\section{HASIL DAN PEMBAHASAN}

\section{Mengintensifkan Wajib Lapor Pecandu Narkotika}

Untuk mendeteksi penyalahguna Narkoba, disamping dengan pelaksanaan test Narkoba dimaksud, para pecandu Narkoba yang sudah dewasa ataupun yang belum dewasa dihimbau agar segera melaporkan kasus kecanduannya untuk menjalani terapi rehabilitasi ditempattempat terapi rehabilitasi. Proses melaporkan diri itulah yang disebut wajib lapor. Kegiatan wajib lapor ini diatur dengan Peraturan Pemerintah Nomor 25 Tahun 2011 tentang Pelaksanaan Wajib Lapor Pecandu Narkotika. Wajib lapor adalah kegiatan melaporkan diri yang dilakukan oleh pecandu Narkotika yang sudah cukup umur atau keluarganya, dan atau oran tua atau wali dari pecandu Narkotika yang belum cukup umur kepada institusi penerima wajib lapor untuk mendapatkan pengobatan dan atau perawatn melalui rehabilitasi medis dan rehabilitasi sosial.

Wajib Lapor Pecandu Narkotika dilakukan di Institusi Penerima Wajib Lapor; Pusat kesehatan masyarakat, rumah sakit dan atau lembaga rehabilitasi medis sebagai Institusi Penerima Wajib Lapor ditetapkan oleh Menteri Kesehatan Nomor 1305/MENKES/SK/VI/2011 tentang Institusi Penerima Wajib Lapor. Disamping itu, lembaga rehabilitasi sosial sebagai Institusi Penerima Wajib Lapor 
ditetapkan oleh Menteri yang menyelenggarakan urusan pemerintahan di bidang sosial

Wajib lapor dilakukan dengan melaporkan Pecandu Narkotika kepada Institusi Penerima Wajib Lapor. Dalam hal ini laporan dilakukan selain pada Institusi Penerima Wajib Lapor, petugas yang menerima laporan meneruskannya kepada Institusi Penerima Wajib Lapor. Pecandu yang telah melaksanakan wajib lapor dimaksud, wajib menjalani rehabilitasi medis dan atau rehabilitasi sosial sesuai dengan rencana rehabilitasinya. Rehabilitasi medis dapat dilaksanakan melalui rawat jalan atau rawat inap sesuai dengan rencana rehabilitasi dengan mempertimbangkan hasil asesmen. Rehabilitasi sosial dapat dilaksanakan baik di dalam maupun di luar lembaga rehabilitasi sosial sesuai dengan rencana rehabilitasi dengan mempertimbangkan hasil asesmen.

\section{Tabel 1 Perkembangan Jumlah Pelayanan Per tahun}

\begin{tabular}{|l|c|c|c|}
\hline $\begin{array}{l}\text { Indikator } \\
\text { Kinerja }\end{array}$ & Target & Capaian & \% \\
\hline $\begin{array}{l}\text { Pengguna } \\
\text { Narkoba yang }\end{array}$ & 110 & 457 & 415 \\
lapor diri ke & & & \\
IPWL & & & \\
\hline
\end{tabular}

Bila dibandingkan dengan target kinerja pada indikator kinerja Jumlah pengguna Narkoba yang lapor diri ke IPWL pada tahun anggaran 2015 sebanyak 110 orang, maka pencapaian kinerja BNNP Sulawesi Selatan pada tahun 2015 sudah melebihi target yang telah ditetapkan oleh Kepala BNN dengan capaian sebesar 415 $\%$, dengan demikian maka dapat disimpulkan bahwa implementasi program mengintensifkan jumlah wajib lapor di BNNP Sulawesi Selatan sudah berjalan dengan baik.

Capaian jumlah pelayanan IPWL yang dilaksanakan pada tahun 2012 sampai dengan tahun 2015 akan terlihat perbedaaan yang sangat signifikan karena pada tahun anggaran 2015 terdapat dukungan pemerintah pusat dengan dilaksanakannya Program rehabilitasi 100.000 orang dengan tambahan anggaran pada APBNP untuk mendorong percepatan pencapaian program tersebut secara sederhana perbandingan data layanan instansi Penerima wajib lapor di Sulawesi Selatan dapat disajikan pada tabel 1 .

\section{Tabel 1 Perkembangan Jumlah Pelayanan Per tahun}

\begin{tabular}{|c|c|c|c|c|c|}
\hline \multirow[b]{2}{*}{ No. } & \multirow{2}{*}{ IPWL } & \multicolumn{4}{|c|}{ JUMLAH LAYANAN/TAHUN } \\
\hline & & 2012 & 2013 & 2014 & 2015 \\
\hline 1. & Klinik Pratama Adi Pradana/BNNP SS & 25 & 45 & 43 & 353 \\
\hline 2. & Klinik BNN Kota Palopo & 0 & 1 & 2 & 22 \\
\hline 3. & Klinik BNN Kabupaten Tana Toraja & 0 & 0 & 0 & 31 \\
\hline 4. & Rumah Sakit Andi Makkasau Pare & 0 & 0 & 0 & 12 \\
\hline 5. & Rumah Sakit Sultan Daeng Raja & 0 & 0 & 0 & 0 \\
\hline 6. & Rumah sakit Salewangan Maros & 0 & 0 & 0 & 0 \\
\hline $\begin{array}{l}7 . \\
8 .\end{array}$ & $\begin{array}{l}\text { Rumah Sakit Bhavanakara } \\
\text { Rumah Sakit Wahidin Sudiro Husodo }\end{array}$ & $\begin{array}{l}0 \\
0\end{array}$ & $\begin{array}{l}0 \\
0\end{array}$ & $:$ & $0_{0}^{2}$ \\
\hline 9. & Rumah Sakit Khusus Daerah Sulsel & 0 & 0 & 0 & 2 \\
\hline 10. & Puskesmas Jumpandang Baru & 0 & 0 & 0 & 0 \\
\hline 11. & Puskesmas Kassi-Kassi & 0 & 0 & 0 & \\
\hline 12. & Puskesmas Jongayya & 0 & 0 & 0 & 0 \\
\hline 13. & Balai Rehabilitasi Baddoka & 0 & 0 & 0 & 0 \\
\hline 14. & YKP2N & 0 & 0 & 0 & 28 \\
\hline 15. & Doulos & 0 & 0 & 0 & 7 \\
\hline & TOTAL LAYANAN & 25 & 46 & 45 & 457 \\
\hline
\end{tabular}

Dan bila disandingkan dengan target jangka menengah pada Peta kinerja BNN Provinsi Sulawesi Selatan periode 2015 2019 yakni sebanyak 70 orang pada tahun 2015, maka dapat disimpulkan pencapaian pada tahun 2015 melebihi target yang telah ditetapkan.

Peningkatan jumlah wajib lapor yang terjadi di tahun 2015 merupakan bukti kesuksesan program rehabilitasi pemerintah 100.000 orang. Dan dengan program tersebut telah mampu merubah cara pandang masyarakat terhadap para penyalahguna narkotika, mereka tidak dianggap lagi sebagai orang pesakitan, sampah masyarakat atau sebagai kriminal yang harus dijauhi tetapi memandang mereka sebagai korban yang harus diselamatkan dan untuk itu maka masyarakat tergerak untuk mendampingi para penyalahguna untuk melaporkan diri ke institusi penerima wajib lapor dengan harapan mereka dapat direhabilitasi.

\section{Pelayanan Rehabilitasi}

Rehabilitasi Penyalah guna Narkoba terbagi dua, yaitu Rehabilitasi Medis dan 
Rehabilitasi Sosial. Rehabilitasi Medis adalah suatu proses kegiatan terapi secara terpadu untuk membebaskan pecandu narkotika dari ketergantungan narkotika. Sedangkan Rehabilitasi Sosial adalah suatu proses kegiatan pemulihan secara terpadu, baik fisik, mental maupun sosial, agar bekas pecandu narkotika dapat kembali melaksanakan fungsi sosial dalam kehidupan bermasyarakat.

Pada indikator kinerja "jumlah layanan terapi dan rehabilitasi" artinya adalah penyalah guna dan/ atau pecandu narkotika (teratur pakai dan pecandu) yang mendapat rekomendasi IPWL BNNP Sulawesi Selatan maupun Tim Assesmen Terpadu (TAT) Sulawesi Selatan untuk mengikuti program terapi dan rehabilitasi di lembaga rehabilitasi BNN, lembaga kesehatan maupun lembaga masyarakat dengan kriteria/ norma pengukuran.

a. Orang yang datang ke IPWL BNNP

Sulawesi Selatan sebagai inisiatif pribadi dan/atau keluarga (voluntary) untuk direkomendasikan mengikuti program terapi dan rehabilitasi pada Balai Rehabilitasi BNN, lembaga kesehatan dan lembaga masyarakat.

b. Orang yang diantar oleh institusi penegak hukum ke Tim Assesmen Terpadu (TAT) Sulawesi Selatan untuk direkomendasikan untuk menjalani rehabilitasi berdasarkan keputusan hakim atau vonis pengadilan (compulsary).

Tabel 2 Perbandingan Layanan Terapi dan Rehabilitasi Penyalah Guna/ Pecandu Narkotika di Sulawesi Selatan Tahun 2012-2014

\begin{tabular}{|l|c|c|l|c|}
\hline \multicolumn{5}{|c|}{ Penyalah Guna Narkotika 2012 } \\
\hline \multicolumn{3}{|c|}{ VOLUNTARY } & \multicolumn{2}{|c|}{ COMPULSARY } \\
\hline Uraian & RI & RJ & \multicolumn{1}{|c|}{ Uraian } & Jumlah \\
\hline $\begin{array}{l}\text { TR. } \\
\text { Baddoka }\end{array}$ & 25 & 0 & $\begin{array}{l}\text { Proses } \\
\text { Pengadilan }\end{array}$ & 0 \\
\hline $\begin{array}{l}\text { RSKD } \\
\text { Sulsel }\end{array}$ & 0 & 0 & $\begin{array}{l}\text { Vonis } \\
\text { Hakim }\end{array}$ & 0 \\
\hline $\begin{array}{l}\text { Klinik Adi } \\
\text { Pradana }\end{array}$ & 0 & & Titipan & 0 \\
\hline DOULOS & 0 & 0 & & 0 \\
\hline YKP2N & 0 & 0 & & 0 \\
\hline Jumlah & $\mathbf{2 5}$ & $\mathbf{0}$ & & $\mathbf{0}$ \\
\hline
\end{tabular}

\begin{tabular}{|c|c|c|c|c|}
\hline \multicolumn{5}{|c|}{ Penyalah Guna Narkotika 2013} \\
\hline \multicolumn{3}{|c|}{ VOLUNTARY } & \multicolumn{2}{|c|}{ COMPULSARY } \\
\hline Uraian & RI & $\mathrm{RJ}$ & Uraian & Jumlah \\
\hline $\begin{array}{l}\text { TR. } \\
\text { Baddoka }\end{array}$ & 45 & 0 & $\begin{array}{l}\text { Proses } \\
\text { Pengadilan }\end{array}$ & 0 \\
\hline $\begin{array}{l}\text { RSKD } \\
\text { Sulsel }\end{array}$ & 0 & 0 & $\begin{array}{l}\text { Vonis } \\
\text { Hakim }\end{array}$ & 0 \\
\hline $\begin{array}{l}\text { Klinik Adi } \\
\text { Pradana }\end{array}$ & 0 & & Titipan & 0 \\
\hline DOULOS & 0 & 0 & & 0 \\
\hline YKP2N & 0 & 0 & & 0 \\
\hline Jumlah & 25 & $\mathbf{0}$ & & $\mathbf{0}$ \\
\hline \multicolumn{5}{|c|}{ Penyalah Guna Narkotika 2013} \\
\hline \multicolumn{3}{|c|}{ VOLUNTARY } & \multicolumn{2}{|c|}{ COMPULSARY } \\
\hline Uraian & RI & $\mathrm{RJ}$ & Uraian & Jumlah \\
\hline $\begin{array}{l}\text { TR. } \\
\text { Baddoka }\end{array}$ & 25 & 0 & $\begin{array}{l}\text { Proses } \\
\text { Pengadilan }\end{array}$ & 0 \\
\hline $\begin{array}{l}\text { RSKD } \\
\text { Sulsel } \\
\end{array}$ & 0 & 0 & $\begin{array}{l}\text { Vonis } \\
\text { Hakim }\end{array}$ & 0 \\
\hline $\begin{array}{l}\text { Klinik Adi } \\
\text { Pradana }\end{array}$ & 0 & & Titipan & 0 \\
\hline DOULOS & 0 & 0 & & 0 \\
\hline YKP2N & 0 & 0 & & 0 \\
\hline Jumlah & 25 & $\mathbf{0}$ & & $\mathbf{0}$ \\
\hline
\end{tabular}

Sumber: Bidang Pemberdayaan Masyarakat

Dari data perkembangan penyalahguna Narkotika dari tahun 20122014 tersebut, maka dapat disimpulkan bahwa Orang yang datang ke IPWL BNNP Sulawesi Selatan sebagai inisiatif pribadi dan/atau keluarga (voluntary) untuk direkomendasikan mengikuti program terapi dan rehabilitasi pada Balai Rehabilitasi BNN, lembaga kesehatan dan lembaga masyarakat, jumlahnya dari tahun ke tahun terus meningkat dibandingkan dengan jumlah orang yang diantar oleh institusi penegak hukum ke Tim Assesmen Terpadu (TAT) Sulawesi Selatan untuk direkomendasikan untuk menjalani rehabilitasi berdasarkan keputusan hakim atau vonis pengadilan (compulsary). Kondisi ini cukup menggembirakan sebab seiring peningkatan secara kuantitas jumlah penyalahguna yang direhabilitasi secara voluntary menunjukkan juga bahwa terjadi peningkatan kesadaran masyarakat akan pentingnya penyalahguna narkotika untuk direhabilitasi.

Hal ini sejalan dengan pendapat Djamaluddin selaku kepala bidang 
pencegahan dan pemberdayaan masyarakat BNNP Kota Makassar, bahwa:

Saat ini masyarakat sudah tidak merasa takut lagi untuk melaporkan kerabat atau orang terdekat lainnya ke institusi penerima wajib lapor sebab ada keyakinan bahwa penyalahguna saat ini lebih diarahkan untuk direhabilitasi daripada di penjara. Dan karena rehabilitasi jauh lebih baik dari pada penjara. (wawancara tanggal 14 September 2016).

Berikut ini akan dijelaskan beberapa alasan mengapa pecandu dan penyalah guna narkoba sebaiknya di Rehabilitasi :

1. Jika kita mengatakan bahwa penyalah guna dan pecandu adalah pelanggar hukum, itu benar tapi mereka bukanlah penjahat, mereka hanyalah korban dari bujuk rayu para pengedar dan bandar. Sifat adiktif yang terkandung didalam narkoba, membuat para penyalah guna dan pecandu ketergantungan untuk mengkonsumsi narkoba.

2. Penggunaan narkoba yang terusmenerus akan berdampak pada kerusakan fisik seseorang, mudah terserang penyakit dan bisa merusak system saraf pusat sehingga membuat mereka menjadi gila atau keterbelakangan mental bahkan menimbulkan kematian. Dengan demikian, bisa dikatakan bahwa penyalah guna dan pecandu narkoba merupakan orang sakit yang harus kita tolong dan disembuhkan dari ketergantungannya sebelum efek narkoba mematikan fungsi otaknya.

3. Berbicara tentang narkoba, berarti berbicara tentang supply and demand. Semakin banyak (demand) permintaan berarti narkoba akan terus ada atau bertambah (supply). Merehabilitasi penyalah guna dan pecandu narkoba hingga sembuh adalah suatu langkah untuk menekan permintaan. Jika sudah tidak ada permintaan dari konsumennya, pengedar dan bandar akan gulung tikar dengan sendirinya.

4. Berdasarkan penelitian BNN RI, setiap harinya 40-50 generasi bangsa Indonesia meninggal dunia karena narkoba. 1,2 juta jiwa sudah tidak bisa dilakukan rehabilitasi karena kondisinya yang terlalu parah. Langkah merehabilitasi penyalah guna dan pecandu narkoba adalah salah satu langkah agar bangsa Indonesia tidak kehilangan generasinya kembali.

Pada tahun 2015 Badan Narkotika Nasional meluncurkan program Rehabilitasi 100.000 orang, maka untuk melihat perbandingan jumlah penyalahguna yang direhabilitasi berikut ini akan dibahas jumlah penyalahguna yang direhabilitasi pada tahun 2015 setelah sebelumnya di bahas data rehabilitasi di tahun 2014.

Tabel 3 Distribusi Rehabilitasi Penyalah Guna Narkoba Berdasarkan Jenis Layanan pada Lembaga Institusi Pemerintah di Sulawesi Selatan Tahun 2015

\begin{tabular}{|c|c|c|c|c|c|c|c|c|c|}
\hline \multirow{2}{*}{ INSTANSI } & \multicolumn{3}{|c|}{ RAWAT INAP } & \multicolumn{3}{|c|}{ RAWAT JALAN } & \multicolumn{3}{|c|}{ TAT } \\
\hline & TARGET & REAL & $\%$ & TARGET & REAL & $\%$ & TARGET & REAL & $\%$ \\
\hline & & & & & & & & & \\
\hline 1 SPN & 100 & 46 & 46,00 & 0 & & & 0 & & \\
\hline $\begin{array}{l}2 \text { LAPAS } \\
\end{array}$ & 240 & 193 & 80,42 & 0 & & & 0 & & \\
\hline 3 RINDAMII & 400 & 38 & 9,50 & 0 & & & 0 & & \\
\hline 4 PUSDIKLAT & 0 & & & 0 & & & 0 & & \\
\hline 5 RS/RSKO & 0 & & 3 & 1210 & 40 & 3,31 & 0 & & \\
\hline \begin{tabular}{l|l|l|l|l|l|l}
6 \\
\end{tabular} & & 1 & & & & & & & \\
\hline \begin{tabular}{l|l|}
7 RSJ/RSKD \\
\end{tabular} & 0 & 2 & & 20 & 7 & 35,00 & 0 & & \\
\hline 8 PUSKESMAS & 0 & & & 200 & 11 & 5,50 & 0 & & \\
\hline \begin{tabular}{|l|l|}
$9 L L N I K$ BNNP \\
\end{tabular} & 0 & & & 155 & 341 & 220,00 & 55 & 155 & 281,82 \\
\hline \begin{tabular}{l|l|l|l|}
10 & KLINIK BNNK \\
\end{tabular} & 0 & & & 30 & 35 & 116,67 & 19 & 7 & 36,84 \\
\hline 11 BNN BADDOKA & 0 & 251 & & & & & & & \\
\hline \begin{tabular}{l|l}
12 & RS BAYANGKARA \\
\end{tabular} & 0 & 2 & & & & & & & \\
\hline \begin{tabular}{|l|l|} 
TOTAL \\
\end{tabular} & 740 & 533 & 72,03 & 1615 & 434 & 26,87 & 74. & 162 & 218,92 \\
\hline
\end{tabular}

Berdasarkan tabel 5.12 di atas, distribusi rehabilitasi penyalah guna narkoba berdasarkan jenis layanan pada Lembaga Institusi Pemerintah di Wilayah Sulawesi Selatan, tercatat total Rawat Inap yang ditargetkan sebanyak 740 orang, dan terealisasi sebanyak 533 orang (72,03\%), kemudian Rawat Jalan (RJ) yang ditargetkan sebanyak 1.615 orang dan terealisasi sebanyak 434 orang $(26,87 \%)$, sedangkan kasus rehabilitasi terkait hukum 
dilaksanakan melalui Tim Asesmen Terpadu awalnya hanya ditargetkan sebanyak 74 orang, namun yang terealisasi sebanyak 162 orang $(218,92 \%)$, artinya terjadi kelebihan 88 orang.

Dari data perkembangan jumlah penyalahguna yang direhabilitasi di tahun 2015 tersebut jelas menunjukkan bahwa terjadi peningkatan yang cukup tinggi apabila dibandingkan dengan rekap data di tahun 2014. Peningkatan jumlah tersebut menurut Djamaluddin bahwa:

Untuk mensukseskan program rehabilitasi 100.000 orang maka pihak BNNP Sulawesi Selatan menyelenggarakan sejumlah perjanjian (MoU) dengan beberapa pihak lembaga pemerintah, non pemerintah dan semua jenjang pendidikan baik di tingkat SD maupun perguruan tinggi dalam upaya mensosialisasikan tentang bahaya narkoba dengan memberikan pengetahuan dan pemahaman yang komprehensif. Sehingga diharapkan di tahun-tahun berikutnya jumlah yang direhabilitasi terus meningkat.

\section{Pembangunan Kapasitas Lembaga Rehabilitasi}

Indikator diatas diukur dengan tujuan untuk mengetahui efektifitas pemberdayaan masyarakat dalam hal mendorong pembentukan lembaga rehabilitasi dan pascarehabilitasi komponen masyarakat di wilayah provinsi Sulawesi selatan pada tahun 2015. Bidang Rehabilitasi telah melaksanakan kerjasama dengan 4 (empat) Lembaga Rehabilitasi Komponen Masyarakat antara lain:

Tabel 4. Badan Narkotika Nasional Provinsi Sulawesi Selatan bekerjasama dnengan Lembaga Masyarakat

\begin{tabular}{|c|l|l|r|}
\hline No & $\begin{array}{c}\text { Nama } \\
\text { Lembaga }\end{array}$ & Tanggal KS & $\begin{array}{c}\text { Jumlah } \\
\text { Layanan }\end{array}$ \\
\hline 1 & LPAB & Juni 2015 & 157 orang \\
\hline 2 & LPAIC & Nov 2015 & 5 orang \\
\hline 3 & $\begin{array}{l}\text { Yayasan } \\
\text { A'bulo } \\
\text { Sibatang }\end{array}$ & 26 Okt 2016 & 25 orang \\
\hline 4. & LP4 & & 46 orang \\
\hline
\end{tabular}

Berdasarkan tabel 4 dapat diuraikan bahwa terhitung sejak bulan juni 2015 Badan Narkotika Nasional Provinsi Sulawesi Selatan telah melakukan kerjasama dengan Lembaga Komponen Masyarakat yaitu LPAB dengan kategori rawat inap yang terealisasi sampai desember sebanyak 157 klien.

Yayasan A'bulo Sibatang dengan kategori rawat inap yang terealisasi sampai desember sebanyak 25 klien, Lembaga Komponen Masyarakat LP4 yang terealisasi sebanyak 46 klien, sedangkan untuk Lembaga Komponen Masyarakat LPAIC dengan kategori rawat inap sebanyak 5 orang.

Tabel 5 Lembaga Rehabilitasi dan Pascarehabilitasi

\begin{tabular}{|c|l|c|c|c|}
\hline No & $\begin{array}{l}\text { Indikator } \\
\text { Kinerja }\end{array}$ & Target & Capaian & $\%$ \\
\hline 1. & $\begin{array}{l}\text { Lembaga } \\
\text { Rehabilitasi } \\
\text { dan }\end{array}$ & 1 & 4 & 400 \\
$\begin{array}{l}\text { Pascarehabi } \\
\text { litasi milik } \\
\text { masyarakat } \\
\text { yang } \\
\text { terbentuk }\end{array}$ & & & & \\
\hline
\end{tabular}

Bila dibandingkan dengan realisasi kinerja pada tahun 2014 diketahui Lembaga Rehabilitasi Komponen Masyarakat di wilayah Sulawesi Selatan terdiri dari 2 Yayasan yaitu: Yayasan Doulos Perwakilan Makassar dan Yayasan Kelompok Peduli Penyalahgunaan Narkoba (YKP2N) Sulawesi Selatan. Dari kedua lembaga tersebut diketahui telah melaksanakan layanan rawat inap terhadap 4 orang pecandu narkoba sebagaimana Data Voluntary dan Compulsary Berdasarkan Status Rawat Inap atau Rawat Jalan di Sulawesi Selatan Tahun 2014.

Dari capain kinerja yang telah dipaparkan diatas bila dibandingkan dengan target capaian pada dokumen renstra Badan Narkotika Nasional Provinsi Sulawesi Selatan Tahun 2015-2019 sebanyak 1 Lembaga telah dicapai sebanyak 4 Lembaga, jadi Satuan Kerja Wilayah Badan Narkotika Nasional 
Provinsi Sulawesi Selatan pada tahun 2015 telah melampaui target sebesar 400 persen.

Pencapaian yang melampaui target pembentukan/kerjasama lembaga rehabilitasi tersebut menurut Bambang selaku kepala sub bagian Perencanaan bahwa:

Kinerja yang menggembirakan tersebut merupakan hasil dari upaya untuk menyukseskan program rehabilitasi 100.000 orang, dan dengan bertambahnya jumlah lembaga rehabilitasi maka diharapkan dapat mengurangi jumlah penyalahguna yang di penjara sebab saat ini antara 60 sampai dengan $70 \%$ penghuni lembaga pemasyarakatan (LAPAS) adalah penyalahguna narkoba dan mereka bukan bandar tetapi korban yang seyogyanya harus kita selamatkan dengan cara di rehabilitasi. (wawancara tanggal 14 September 2016).

Lembaga rehabilitasi merupakan tempat terbaik bagi para penyalahguna yang merupakan korban dari para pengedar atau bandar dan lembaga tersebut harus dikelola dengan baik sebagaimana hal tersebut telah tertuang dalam Peraturan Pemerintah Republik Indonesia nomor 25 tahun 2011 Pasal 15 bahwa setiap penyelenggara program rehabilitasi harus menyusun standar prosedur operasional penatalaksanaan rehabilitasi sesuai dengan jenis dan metode terapi yang digunakan dengan mengacu pada standar dan pedoman penatalaksanaan rehabilitasi.

\section{Pembinaan Lanjut Kepada Mantan Penyalahguna, Korban Penyalahgunaan Dan Pecandu Narkoba.}

Rehabilitasi berkelanjutan adalah tahapan bina lanjut (after care) yang merupakan serangkaian kegiatan positif dan produktif bagi penyalahguna/pecandu narkotika pasca menjalani tahap pemulihan (rehabilitasi medis dan sosial). Tahapan bina lanjut merupakan bagian yang integral dalam rangkaian rehabilitasi ketergantungan narkotika dan tidak dapat dianggap sebagai bentuk terapi yang berdiri sendiri, hal ini berkaitan dengan pemahaman umum bahwa setelah pecandu menjalani program rehabilitasi di tempat rehabilitasi, mereka masih memerlukan pendampingan agar proses reintegrasi ke masyarakat dapat berlangsung sesuai dengan tujuan untuk dapat hidup normatif, mandiri dan produktif.

Pasca rehabilitasi merupakan bagian yang tidak terpisahkan dari proses rehabilitasi berkelanjutan. Pentingnya pelaksanaan program pasca rehabilitasi adalah untuk membantu mantan penyalah guna narkotika untuk kembali hidup di tengah-tengah masyarakat secara normatif, produktif dan mandiri dan dapat berfungsi secara sosial, sehingga dapat mengurangi stigma negatif dari masyarakat terhadap mantan penyalah guna narkotika dan menambah dukungan masyarakat terhadap proses pemulihan.

Layanan pasca rehabilitasi adalah bagian dari rehabilitasi sosial berupa pembinaan lanjut dalam bentuk pendampingan, peningkatan ketrampilan dan dukungan produktivitas agar mampu menjaga kepulihan serta beradaptasi dengan lingkungan sosial dan mandiri.

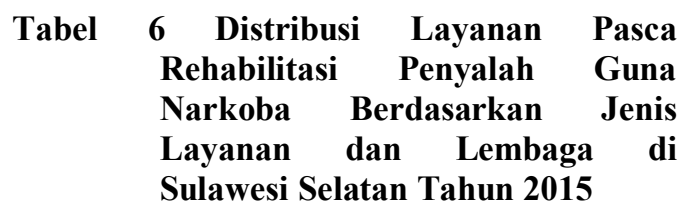

\begin{tabular}{|r|l|r|r|r|r|r|r|}
\hline \multirow{2}{*}{ NO } & \multirow{2}{*}{ INSTANSI } & \multicolumn{3}{|c|}{ RAWAT INAP } & \multicolumn{3}{|c|}{ RAWAT JALAN } \\
\cline { 3 - 8 } & & TARGET & REAL & $\%$ & TARGET & REAL & $\%$ \\
\hline & & & & & & & \\
\hline 1 & RD SUNGGUMINASA & 60 & 0 & 0,00 & 0 & & \\
\hline 2 & $\begin{array}{l}\text { KONSERVASIALAM } \\
\text { BENGO }\end{array}$ & 100 & 22 & 22,00 & 0 & & \\
\hline 3 & RD YKP2N & 65 & 75 & 115,38 & 0 & & \\
\hline 4 & BAPAS & & & & 300 & 175 & 58,3 \\
\hline 5 & LAYANAN BNNP/K & 0 & 0 & & 225 & 146 & 64,9 \\
\hline & & & & & & & \\
\hline & TOTAL & 225 & 97 & 43,11 & 525 & 321 & 65 \\
\hline
\end{tabular}

Berdasarkan Tabel 6, diuraikan bahwa distribusi layananan Pasca Rehabilitasi penyalah guna narkoba berdasarkan jenis layanan per lembaga di wilayah Sulawesi Selatan pada tahun 2015 sebanyak 418 klien dari target 750 klien (capaian 55,7\%). Layanan pasca 
rehabilitasi Rawat Inap yang ditargetkan sebanyak 225 klien, namun yang terealisasi hanya 97 klien $(43,11 \%)$. Kemudian layanan pasca rehabilitasi Rawat Jalan yang ditargetkan sebanyak 525 klien, terealisasi sebanyak 321 klien (65\%).

Sepanjang tahun 2015, BNNP Sulawesi Selatan telah merujuk 1.280 klien untuk menjalani proses rehabilitasi pada lembaga rehabilitasi institusi pemerintah sebanyak 1.014 klien $(79,21 \%)$ dan lembaga rehabilitasi komponen masyarakat sebanyak 266 klien (20,78\%).

Tabel 7 Persentase Pemulihan Layanan Rehabilitasi Rawat Inap Per Lembaga di Sulawesi Selatan Tahun 2015

\begin{tabular}{|c|c|c|c|c|c|}
\hline \multirow{2}{*}{ No } & \multirow{2}{*}{ LEMBAGA } & \multirow{2}{*}{$\begin{array}{c}\text { TOTAL } \\
\text { RESIDEN }\end{array}$} & \multicolumn{2}{|c|}{ PEMULIHAN } & \multirow{2}{*}{$\%$ PULIH } \\
\hline & & & TDK SELESAI & SELESAI & \\
\hline & BADDOKA & 251 & 0 & 251 & 100,0 \\
\hline 2 & SPN & 47 & 18 & 29 & 61,7 \\
\hline 3 & \begin{tabular}{|l|} 
RINDAM \\
\end{tabular} & 38 & 7 & 31 & 81,6 \\
\hline 4 & BHAYANGKARA & 2 & 0 & 2 & 100,0 \\
\hline 5 & DINSOS & 1 & 0 & 1 & 100,0 \\
\hline 6 & RSKO & 2 & 0 & 2 & 100,0 \\
\hline 7 & LAPAS/RUTAN & 193 & 0 & 193 & 100,0 \\
\hline 8 & YKP2N & 28 & 4 & 24 & 85,7 \\
\hline 9 & LPAB & 157 & 2 & 155 & 98,7 \\
\hline 10 & \begin{tabular}{|l|} 
LP4 \\
\end{tabular} & 46 & 0 & 46 & 100,0 \\
\hline 11 & DOULOS & 7 & 0 & 7 & 100,0 \\
\hline 12 & LPAIC & 5 & 0 & 5 & 100,0 \\
\hline 13 & LASM & 23 & 4 & 19 & 82,6 \\
\hline 14 & YRRCB & 1 & 0 & 1 & 100,0 \\
\hline & JUMLAH & 801 & 35 & 766 & 95,6 \\
\hline
\end{tabular}

Berdasarkan tabel 7, sebanyak 801 klien yang terdaftar mengikuti proses rehabilitasi, hanya 766 klien $(95,6 \%)$ yang dinyatakan berhasil menyelesaikan program rehabilitasi (pulih), dan sebanyak 35 klien yang tidak menyelesaikan proses rehabilitasi karena meninggalkan lembaga rehabilitasi.

Tabel 8 Persentase Pemulihan Layanan Rehabilitasi Rawat Jalan Per Lembaga di Sulawesi Selatan Tahun 2015

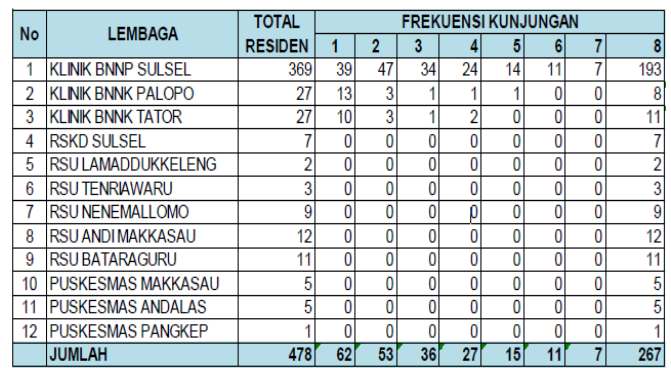

Berdasarkan tabel 8 menunjukkan layanan rehabilitasi rawat jalan hanya mencapai $55,74 \%$ yang dinyatakan pulih (menyelesaikan proses rehabilitasi rawat jalan), sisanya $12,94 \%$ berkunjung hanya satu kali, $11,06 \%$ berkunjung hanya 2 kali, $7,52 \%$ berkunjung hanya tiga kali, 5,64\% berkunjung hanya empat kali, 3,13\% berkunjung hanya 5 kali, 2,30 berkunjung hanya 6 kali, 1,46 berkunjung hanya 7 kali.

Implementasi pembinaan lanjut penyalahguna narkoba dapat dikategorikan berjalan dengan baik karena secara keseluruhan, residen yang menyelesaikan proses rehabilitasi baik rawat inap maupun rawat jalan di Wilayah Sulawesi Selatan sebanyak 1.033 klien (80,70\%).

Jumlah layanan mantan pecandu narkotika yang dilakukan BNNP Sulawesi Selatan pada tahun 2014 sebanyak 25 orang yang dilakukan pembinaan secara kelompok sebanyak 6 kali pada tahun 2014. Norma pengukurannya adalah jumlah mantan pecandu narkotika yang dibina supaya tidak kambuh lagi menjadi pengguna narkotika. Capaian jumlah mantan pecandu narkotika yang dibina dari tahun 2012-2014 terlihat stagnan pada angkaa 25 orang mantan pecandu narkotika.

Hasil yang dicapai para mantan penyalah guna narkotika yang mengikuti program pembinaan kelompok yaitu semakin menguatnya kepercayaan diri bagi masing-masing mantan pecandu untuk menghadapi kehidupan saat kembali ke lingkungan masyarakat melalui kegiatan rutin.

\section{KESIMPULAN}

Berdasarkan hasil penelitian dan pembahasan maka kesimpulan yang diambil dari hasil penelitian ini adalah:

1. BNNP Sul-Sel telah berhasil menjalankan progran mengintensifkan wajib lapor pecandu narkotika, hal tersebut ditunjukkan dalam capaian kinerja $435 \%$ karena jumlah wajib 
lapor melampaui target yang tekah ditetapkan sebelumnya.

2. Pelayanan rehabilitasi medis dan rehabilitasi sosial telah berhasil dijalankan dengan baik, hal ini dapat dilihat dalam pencapaian jumlah penyalahguna yang direhabilitasi terus meningkat. Dengan dipertegas oleh program rehabilitasi 100.000 orang. Persentase kepulihan dari klien yang mengikuti proses rehabilitasi di Sulawesi Selatan sebesar $80,70 \%$ atau melebihi standar keberhasilan nasional yaitu $60 \%$.

3. Pembangunan kapasitas rehabilitasi medis dan rehabilitasi sosial, sejak didirikannya BNNP Sulawesi Selatan Mei 2010 sampai dengan 2015, telah mampu membangun/bekerjasama dengan sejumlah lembaga rehabilitasi yaitu 4 lembaga.

4. Pembinaan lanjut kepada mantan penyalahguna narkotika masih belum menunjukkan capaian kinerja yang baik sebab pada tahun 2015 presentase kinerja hanya sekitar 55,7 \% dari target yang telah ditetapkan. Pembinaan lanjut diharapkan bisa membantu meningkatkan kesiapan fisik dan psikis mantan penyalahguna narkotika untuk kembali dalam kehidupan sosial bermasyarakat dan dapat menjadi manusia yang produktif.

\section{DAFTAR PUSTAKA}

Agustino Leo. (2008). Dasar-dasar Kebijakan Publik. Bandung: Alfabeta

Anggara. (2012). Penyelenggaraan Makanan di Rumah Sakit. Jakarta: Bumi Aksara

Ghony, M.D. dan Almanshur, F. (2002). Metodologi Penelitian Kualitatif, Yogyakarta: Ar-ruzz Media.

Instruksi Presiden Republik Indonesia Nomor 12 Tahun 2011 Tentang Pelaksanaan Kebijakan dan Strategi Nasional Pencegahan dan
Pemberantasan Penyalahgunaan dan Peredaran Gelap Narkoba.

Nugroho, Riant. (2003). Kebijakan Publik Formulasi, Implementasi dan Evaluasi. PT.Elek Media Komputindo. Jakarta

Peraturan Pemerintah Republik Indonesia Nomor 25 Tahun 2011 Tentang Pelaksanaan Wajib Lapor Pecandu Narkotika.

Peraturan Presiden Nomer 23 Tahun 2010 tentang badan Narkotika Nasional

Syafi'ie, (2000). INU Kencana, Al-Qur'an dan Ilmu Administrasi, Jakarta: Rineka Cipta.

Solihin, A.M. (2007). Pengaruh Motivasi Kerja dan Kompetensi Pedagogik terhadap Kinerja Mengajar Guru Bantu (Studi Kasus pada Sekolah Menengah Pertama di Kabupaten Tasikmalaya. Tesis. Program Pascasarjana UPI. Tidak diterbitkan.

Tachjan, Dr. H,. (2006). Implementasi Kebijakan Publik. AIPI. Bandung

Winarno, Budi. (2008). Kebijakan Publik Teori dan Proses. Jakarta: PT Buku Kita 